\title{
Is there a Demand of Conducting Agent of Acetylene Black for Graphene- Wrapped Natural Spherical Graphite as Anode Material for Lithium-Ion Batteries?
}

\author{
Xuewei Liu 1,2,†, Ying Niu ${ }^{2, \dagger}$, Ruixiong Cao ${ }^{1,2}$, Xiaohong Chen ${ }^{1,2}$, Hongyan Shang ${ }^{3}$, Huaihe Song ${ }^{1,2,{ }^{*}}$ \\ ${ }^{1}$ Changzhou Institute of Advanced Materials, Beijing University of Chemical Technology, Changzhou 213164, \\ Jiangsu Province, China. \\ ${ }^{2}$ State Key Laboratory of Chemical Resource Engineering, Beijing Key Laboratory of Electrochemical Process and Technology for \\ Materials, Beijing University of Chemical Technology, Beijing 100029, China. \\ ${ }^{3}$ College of Science, China University of Petroleum, Qingdao 266580, Shandong Province, China.
}

\begin{abstract}
Graphene-wrapped natural spherical graphite (G/SG) composites were prepared using the encapsulation-carbonization approach. The morphology and structure of the composites were characterized by scanning electron microscopy and X-ray diffraction analysis. The electrochemical performance of the composites with different graphene contents as anode materials for lithium-ion batteries was investigated by various electrochemical techniques. In the absence of acetylene black $(A B)$, the G/SG composites were found to exhibit high specific capacity with high first-cycle coulombic efficiency, good cycling stability, and high rate performance. Compared with the natural spherical graphite (SG) electrode, the G/SG composite electrode with $1 \%$ graphene exhibited higher reversible

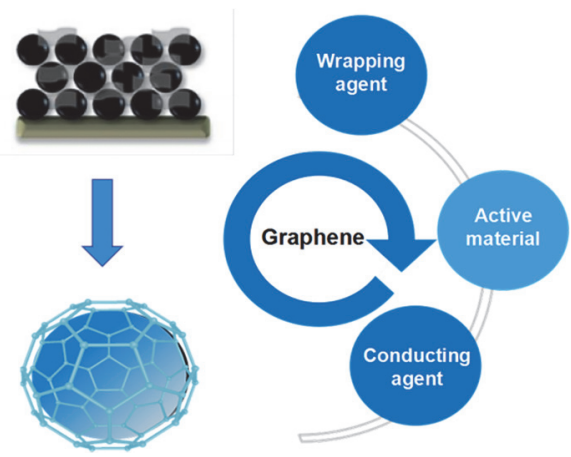
capacity after 50 cycles; this capacity performance was equal to that of the SG $+10 \% \mathrm{AB}$ electrode. Moreover, when the addition of $2.5 \%$ graphene, the composite electrode exhibited higher initial charge capacity and reversible capacity during 50 cycles than the SG+10\%AB electrode. The significant improvement of the electrochemical performance of the G/SG composite electrodes could be attributed to graphene wrapping. The graphene shell enhances the structural integrity of the natural SG particles during the lithiation and delithiation processes, further improving the cycling stability of the composites. Moreover, the bridging of adjacent SG particles allows the formation of a highly conductive network for electron transfer among SG particles. Graphene in the composites serves as not only an active material but also a conductive agent and promotes the improvement of electrochemical performance. When $5 \% \mathrm{AB}$ was added, the reversible capacity of the $5 \% \mathrm{G} / \mathrm{SG}$ electrodes significantly increased from 381.1 to $404.5 \mathrm{mAh} \cdot \mathrm{g}^{-1}$ after 50 cycles at a rate of $50 \mathrm{~mA} \cdot \mathrm{g}^{-1}$ and from 82.5 to $101.9 \mathrm{mAh} \cdot \mathrm{g}^{-1}$ at $1 \mathrm{~A} \cdot \mathrm{g}^{-1}$, suggesting that $A B$ addition improves the performance of the $\mathrm{G} / \mathrm{SG}$ composite electrodes. $A B$ particles connect to G/SG particles through point contact type and fill the gaps between G/SG. A more effective conductive network is synergistically formed via graphene-AB connection. Although graphene wrapping and $A B$ addition improve the performance of natural graphite electrodes, such as through increase in electrical conductivity and enhancement of Li-storage performance, including improvement of reversible capacity, rate performance, and cycling stability, electrode density typically decreases with graphene or AB addition, which should consider the balance between the gravimetric and volumetric capacities of graphite anode materials in practical applications. These results have great significance for expanding the commercial application scope of natural graphite. Our work provides new understanding and insight into the electrochemical behavior of natural SG electrodes in lithium-ion batteries and is helpful for the fabrication of high-performance anode materials.
\end{abstract}

Received: December 22, 2020; Revised: February 1, 2021; Accepted: February 3, 2021; Published online: February $22,2021$.

${ }^{*}$ Corresponding author. Email: songhh@mail.buct.edu.cn.

tThese authors contributed equally to this work.

The project was supported by the National Natural Science Foundation of China (U1610252, 51911530126).

国家自然科学基金(U1610252, 51911530126)资助项目

(C) Editorial office of Acta Physico-Chimica Sinica 
Key Words: Graphene; Graphene-wrapped; Natural spherical graphite; Lithium-ion battery; Anode material; Conductive agent; Acetylene black

\title{
石墨烯包覆天然球形石墨作为锂离子电池的负极材料, 是否需要乙炔 黑导电剂?
}

\author{
刘学伟 $1,2, \dagger$, 牛荣 $2, \dagger$, 曹瑞雄 ${ }^{1,2}$, 陈晓红 ${ }^{1,2}$, 商红岩 ${ }^{3}$, 宋怀河 ${ }^{1,2, *}$ \\ 1 北京化工大学, 常州先进材料研究院, 江苏常州 213164 \\ 2 北京化工大学化工资源有效利用国家重点实验室, 材料电化学过程与技术北京市重点实验室, 北京 100029 \\ 3 中国石油大学理学院, 山东青岛 266580
}

\begin{abstract}
摘要：我们通过包覆炭化的方法制备得到了石墨烯包覆的天然球形石墨 $(G / S G)$ 材料, 并使用扫描电子显微镜、X 射线衍 射仪以及多种电化学测试手段考察了不同石墨烯含量的复合材料的形貌结构及电化学性能。我们发现, 在不添加乙炔黑 (AB)的情况下, $G / S G$ 复合材料表现出较高的首次库伦效率, 很好的循环稳定性和高倍率性能。当石墨烯包覆量为 $1 \%$ 时, 材料 50 次循环后的可逆容量可与添加 $10 \% A B$ 的天然石墨电极(SG)等同; 当石墨烯包覆量为 $2.5 \%$ 时, 材料的比容量 完全高于添加 10\%AB 的石墨电极。材料电化学性能的改善归因于石墨烯的包覆。一方面, 石墨烯的柔软可变性可以保 证天然石墨颗粒在充放电过程中的结构完整性, 从而有效改善材料的循环稳定性; 另一方面, 石墨烯的存在提高了电极 的导电性, 促进更好导电网络的形成。因此, 石墨烯包覆天然球形石墨材料中, 石墨烯不仅是活性物质, 也发挥导电剂的作 用。当添加 $5 \%$ 的乙炔黑时, 在 $50 \mathrm{~mA} \cdot \mathrm{g}^{-1}$ 电流循环 50 次后, $5 \% \mathrm{G} / \mathrm{SG}$ 电极的可逆容量从 $381.1 \mathrm{mAh} \cdot \mathrm{g}^{-1}$ 提高到 404.5 $\mathrm{mAh} \cdot \mathrm{g}^{-1}$, 在 $1 \mathrm{~A} \cdot \mathrm{g}^{-1}$ 电流时可逆容量从 $82.5 \mathrm{mAh} \cdot \mathrm{g}^{-1}$ 提高到 $101.9 \mathrm{mAh} \cdot \mathrm{g}^{-1}$, 这表明 $\mathrm{G} / \mathrm{SG}$ 电极仍然需要乙炔黑导电剂。 乙炔黑颗粒填充在复合材料的空隙中, 通过点接触的形式连接到 G/SG 颗粒, 与石墨烯协同作用形成了更加有效的导电 网络。尽管石墨烯包覆和乙炔黑添加对天然石墨电极具有积极的影响, 例如增加了天然石墨电极的导电性和储锂性能(包 括可逆容量, 倍率性能和循环性能), 但随着石墨烯或乙炔黑的增加, 电极密度通常会降低。因此, 在实际应用中应考虑 石墨负极材料的质量和体积容量的平衡。这些结果对天然石墨的进一步商业应用具有重要意义。我们的工作为天然石墨 电极在锂电池中的电化学行为提供了一种新的认识, 并且有助于制备更高性能的负极材料。
\end{abstract}

关键词: 石墨烯; 石墨烯包覆; 天然球形石墨; 锂离子电池; 负极材料; 导电剂; 乙炔黑 中图分类号: 0646

\section{Introduction}

After being introduced into the market in the early 1990s, Liion batteries are widely used as the most promising power sources for cell phones, laptop, and other digital equipments. Natural graphite is still considered as an important commercially available anode material due to its flat voltage profile, low cost, and high reversible capacity ${ }^{1}$. However, natural graphite anode suffers from some disadvantages such as its high sensitivity to electrolytes and easy exfoliation ${ }^{2}$, resulting in low initial coulombic efficiency, poor cycling stability and bad rate performance, and making it cannot meet the demands of the applications in electric vehicle and as large-scale power supplies. With this background, modification of graphite has become a necessary issue to improve its electrochemical performance. The disadvantages above may be overcomed by surface oxidation ${ }^{3,4}$, doping other elements ${ }^{5-7}$, or surface coating ${ }^{8-11}$.

To increase the conductivity of electrodes, conductive carbon additives are always required in anode system. Conventional conductive additives mainly include conductive graphite and carbon black. Graphene, a two-dimensional monolayer of $s p^{2}$ carbon atoms, is regarded as the building unit of graphite. Since the paper on the freestanding graphene was published by Geim and his co-workers ${ }^{12}$ in 2004, graphene has become one of the most fascinating carbon materials due to its excellent electric conductivity, high specific surface area, wonderful structural flexibility, superior thermal conductivity and good chemical stability ${ }^{13,14}$. Because of high electrical conductivity, graphene has been introduced into lithium-ion batteries system both of anode and cathode as an effective conductive additive ${ }^{15-20}$. As a new material, graphene is also used for modification of silicon materials ${ }^{21,22}$, metal oxides ${ }^{23}$ or carbon materials ${ }^{24}$.

Guo et al. ${ }^{18}$ investigated the effects of graphene nanosheet (GNS) addition via mechanical mixing on the electrochemical performance of the artificial graphite (AG) electrode, and found that the graphite electrode loaded with GNS exhibits superior electrochemical performance compared with the graphite electrode which add the traditional conducting agent of acetylene black. But it should be noted that, the first coulombic efficiency of AG with GNS is lower than that of AG with other additives, which could be assigned to the higher surface area, 
functional groups, more defects and micropores of GNS. A comparative investigation was carried out on three kinds of conducting additives, such as carbon black, multiwalled carbon nanotubes and GNS, combining with spherical natural graphite by direct adding method as an anode material by Li et al. ${ }^{19}$. When GNS addition fraction is $5 \%$, the first charge capacity was $366 \mathrm{mAh} \cdot \mathrm{g}^{-1}$ at $0.1 \mathrm{C}$ and the initial cycle efficiency was only $67 \%$. And they only investigated the reversible capacity in 20 cycles. Then their team made a comparison on carbon black and graphene nanosheets as conducting additives in spherical natural graphite ${ }^{20}$. The reversible capacity of natural graphite mixed with $5 \%$ graphene nanosheets increased to $355 \mathrm{mAh} \cdot \mathrm{g}^{-1}$ and the cycle stability in 30 cycles was improved to $97 \%$. But they didn't investigate the rate performance. And the addition fraction is higher for application. However, the above-mentioned reports concentrate on the effects of graphene addition on electrochemical properties by adding graphene sheets directly into graphite powder as anode materials. The aggregation of graphene sheets mostly exhibits the properties of graphene particles, other than the intrinsic property of 2D-graphene. Also, the agglomeration of graphene sheets reduces the impact of the excellent structural flexibility of graphene sheets in cycle stability. Liu et al. ${ }^{24}$ synthesized new type of graphite-like carbonaceous anode comprising graphite particles wrapped by large-size nitrogen-doped graphene (LNG) platelets. The reversible capacity of the large-size nitrogen-doped graphenecoated commercial graphite anodes (LGA) with $1 \%$ graphene remained at $360 \mathrm{mAh} \cdot \mathrm{g}^{-1}$ after 100 cycles at $0.1 C$ with a capacity retention of $90 \%$ in $\mathrm{LGA} / \mathrm{LiCoO}_{2}$ full cells. But they used thermal reduced graphene coated graphite anodes, whose capacity hardly improved compared with the pure graphite.

When acting as a conductive agent, the compositional way of graphene and electrode materials also directly affects the electrochemical properties of the electrode. Such as when powders are mixed directly, the graphene is composited in the form of agglomerated powders, which only acts as a conductive agent; And when graphene is compounded in the form of solution, in addition to conductive action, the high flexibility and deformability of graphene can render it a promising coating agent in a lithium-ion battery and promote the electrochemical properties of the electrode to a greater extent. Currently, there are few studies on the effects of the composite method of graphene and electrode materials on electrochemical performance. Is there a demand of conducting agent of acetylene black for graphene-wrapped natural spherical graphite as anode material for lithium-ion batteries? Could graphene replace the function of acetylene black independently? In this paper, we propose a two-step method starting from graphene oxide to prepare graphene-wrapped natural spherical graphite as anode material for lithium-ion batteries. The effects of graphene encapsulation and acetylene black addition in wrapped-graphite anode on the electrochemical performance of spherical graphite anode for Lithium-ion batteries were investigated. The important roles of both graphene and acetylene black in graphite anode were further revealed. Furthermore, to explain the reason for the improvement of electrochemical properties, various analytical techniques were characterized systematically.

\section{Experimental}

\subsection{Preparation of graphene oxide and graphene- wrapped natural spherical graphite}

Graphene oxide (GO) was synthesized via a modified Hummers method ${ }^{25} .5 .0 \mathrm{~g}$ high purity graphite $(45-50 \mu \mathrm{m}$, provided by Qing Dao Tai Chang Graphite Co., Ltd. China) was mixed with $2.5 \mathrm{~g} \mathrm{NaNO}_{3}$ and $150 \mathrm{~mL}$ concentrated sulfuric acid ( $98 \%$ ( $w$, mass fraction)). Then $15.0 \mathrm{~g} \mathrm{KMnO}_{4}$ was added slowly into the above system and stirred for $30 \mathrm{~min}$, and the temperature was kept below $0{ }^{\circ} \mathrm{C}$ in water bath. After that, the temperature changed to $35^{\circ} \mathrm{C}$ and stirred for $6 \mathrm{~h}$. Subsequently, the mixture was slowly added into $300 \mathrm{~mL}$ deionized water and treated with $30 \% \mathrm{H}_{2} \mathrm{O}_{2}$ until the color of the mixture changed to bright yellow. The graphene oxide was collected by centrifuge and purified by dialysis till the waste water at a neutral $\mathrm{pH}$ value.

Graphene-wrapped natural spherical graphite (G/SG) was prepared via a simple two-step method (Fig. 1). Natural spherical graphite (SG, C: $99.9 \%(w)$ ), $D_{50}=12 \mu \mathrm{m}$, provided by Qing Dao Jinrilai Graphite Co., Ltd. China) was first dispersed in ethanol by magnetic stirring, and the as-prepared GO aqueous solution was treated with sonication. Subsequently, the GO aqueous solution was continuously added into the $\mathrm{SG}$ suspensions under magnetic stirring and dispersed uniformly, and then the solvent was evaporated. As solvent evaporated, the amphipathic GO sheets migrate to the surface of SG. Finally, the residue was treated at $700{ }^{\circ} \mathrm{C}$ for $1 \mathrm{~h}$ under nitrogen atmosphere to yield graphene-wrapped spherical graphite. The weight ratio of GO and SG was designed to $x: 100(x=0.5,1,2,5$, and 10). The graphite oxide, which was obtained by freeze drying of GO aqueous solution, was also carbonized at $700{ }^{\circ} \mathrm{C}$ for $1 \mathrm{~h}$ under nitrogen atmosphere. The percentage of weight loss of GO was about $50 \%$, and therefore the weight ratio of graphene and SG was about $x: 100(x=0.25,0.5,1,2.5$, and 5) after reduction.

\subsection{Materials characterizations}

The morphology and structure of the samples were observed by scanning electron microscope (SEM, ZEISS SUPRATM field emission microscope). X-ray diffraction (XRD) measurement was conducted on a Rigaku D/max -2500B2 + /PCX system using $\mathrm{Cu} / K_{\alpha}$ radiation $(\lambda=0.15406 \mathrm{~nm})$ in the range of $2 \theta=5^{\circ}-$ $90^{\circ}$.

The capacities and cycling properties of the samples were carried out by using 2025-type coin cells. The working electrode without conductive agent was prepared by mixing the active material and polyvinylidene difluoride (PVDF) in a weight ratio of $9: 1$ in $N$-methyl-2-pyrrolidinone (NMP) solvent. The working electrode with conductive agent was fabricated by mixing the active component, acetylene black (AB, provided by Huaguang Chemical Plant, China) and PVDF in a weight ratio 


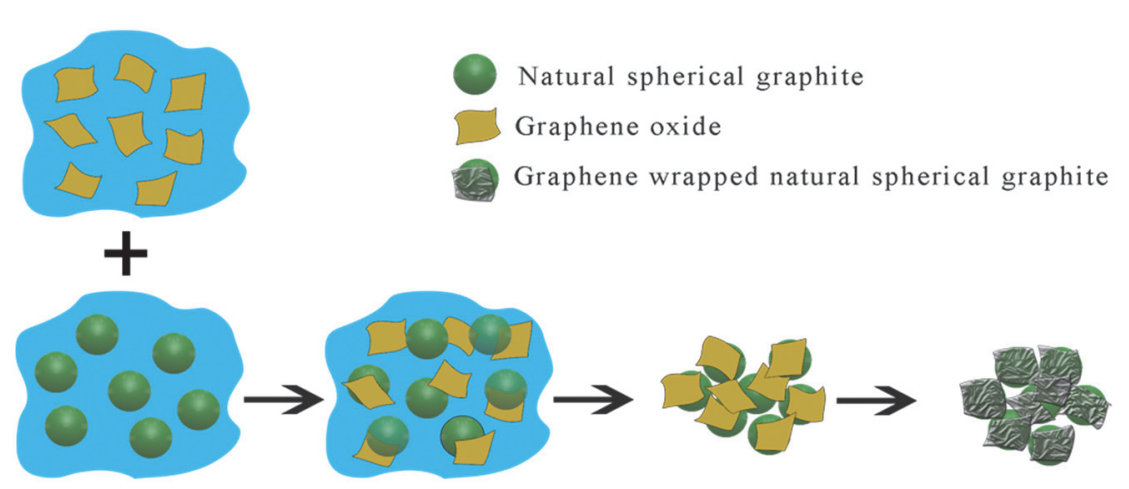

Fig. 1 Schematic illustration of the fabrication of graphene-wrapped spherical graphite.

of $8.5: 0.5: 1$ in NMP solvent. Then the slurry was spread onto foam nickle and dried under vacuum at $80^{\circ} \mathrm{C}$ for $4 \mathrm{~h}$ and $120^{\circ} \mathrm{C}$ for $12 \mathrm{~h}$. A lithium sheet was used as the counter electrode. The electrolyte was a solution of $1 \mathrm{~mol} \cdot \mathrm{L}^{-1} \mathrm{LiPF}_{6}$ in a $1: 1: 1$ volume mixture of ethylene carbonate, dimethyl carbonate and ethylmethyl carbonate (EC/DMC/EMC). Cells were assembled in an argon-filled glove box. The cells were galvanostatically charged and discharged in the voltage range from 0.01 to $2.50 \mathrm{~V}$ (vs. $\mathrm{Li} / \mathrm{Li}^{+}$) at various current densities. Furthermore, we mixed the active material, polyvinylidene difluoride and acetylene black with a mass ratio of $8: 1: 1$ by the similar method as compared electrode. In order to better increase the reliability of the data, all of the charge and discharge data are the average of the parallel test of the three batteries. The electrochemical impedance spectral (EIS) measurements were carried out on a Zahner Zennium electrochemical workstation and recorded by applying a sine wave of $5.0 \mathrm{mV}$ amplitude over the frequency range from $100 \mathrm{kHz}-10 \mathrm{mHz}$.

\section{Results and discussion}

\subsection{Morphology and structure of graphene-wrapped natural spherical graphite}

The morphologies of the pristine SG and G/SG samples at different graphene contents were observed by SEM as shown in Fig. 2. The particles of SG and the coated samples most exhibit uniformly spherical or ellipsoidal shape and are micron in diameter. In every different graphene content images, the graphene can be easily identified as the thin sheets with many folds and wrinkles that wrap the SG particles homogeneously and also bridge nearby particles together. With the increase of graphene loading, there are more graphene can be observed. The morphologies of $(\mathrm{a}, \mathrm{b}) 2.5 \% \mathrm{G} / \mathrm{SG}+5 \% \mathrm{AB}$ and $(\mathrm{c}, \mathrm{d}) 5 \% \mathrm{G} / \mathrm{SG}+$ $5 \% \mathrm{AB}$ are exhibited in Fig. 3. The $\mathrm{AB}$ particles distribute on the surface of the $\mathrm{G} / \mathrm{SG}$ and aggregate in the internal space among $\mathrm{G} / \mathrm{SG}$ particles.

Table 1 shows the tap density and compaction density for SG, $\mathrm{SG}+10 \% \mathrm{AB}, \mathrm{G} / \mathrm{SG}$ and $\mathrm{G} / \mathrm{SG}+5 \% \mathrm{AB}$ with the different graphene contents. As described in Table 1, with the loading content of graphene from $0.25 \%$ to $5 \%$, both the tap density and compaction density of the graphite powders decrease. The low tap density of G/SG is caused by the reduction in the contact interface between each agglomerate particle, which results in more vacancy and poor fluidity of the powders. Similarly, the increase of graphene loading, the compaction density of G/SG powders also decline slightly. Therefore, a very low weight percentage of graphene can fully wrap the graphite particles and improve fluidity of the powders. Conversely, excessive graphene can cause the over-stacking and agglomeration of graphene, adversely affecting the composite properties.

The XRD patterns of the pristine $\mathrm{SG}, \mathrm{GO}$ and $\mathrm{G} / \mathrm{SG}$ samples are shown in Fig. 4. There is a strong peak at about $11^{\circ}$ in the XRD pattern of GO, which is corresponding to the (001) diffraction peak of GO. This peak indicates the existence of abundant oxygen-containing groups, implying that the original graphite has been successful oxidized to GO. It can be seen that all the coated samples have a (002) diffraction peak at $26^{\circ}$, which is similar to that of the pristine SG. This result indicates that their overall crystal structural characteristics are not severely changed after coating. The diffraction peak of GO completely disappears after thermal treatment, suggesting that the GO has been fully reduced to graphene by heat treatment.

\subsection{Electrochemical properties of graphene- wrapped natural spherical graphite}

Fig. 5a shows the first three charge/discharge curves of $5 \% \mathrm{G} / \mathrm{SG}$ at a current density of $50 \mathrm{~mA} \cdot \mathrm{g}^{-1}$. In the first discharge curve (Li-insertion), a voltage plateau at about $0.7 \mathrm{~V}$ can be attributed to the electrolyte decomposition and the solid electrolyte interface (SEI) film formation on the electrode surface ${ }^{26}$. Besides, a long voltage plateau at about $0.2 \mathrm{~V}$ is observed, corresponding to the formation of $\mathrm{LiC}_{6}$. These are the typical charge/discharge curves of graphite due to that the crystal structural characteristics are not severely changed after coating. Cycle performances of $\mathrm{G} / \mathrm{SG}$ at different graphene contents, pure $\mathrm{SG}$ and $\mathrm{SG}+10 \% \mathrm{AB}$ electrodes at a current density of 50 $\mathrm{mA} \cdot \mathrm{g}^{-1}$ for 50 cycles are shown in Fig. $5 \mathrm{~b}$. It can be seen that without any conductive additive, SG electrode exhibits a low reversible capacity and cyclic stability. The first-cycle coulombic efficiency of SG is $78.4 \%$ and the reversible capacity fades to $288.6 \mathrm{mAh} \cdot \mathrm{g}^{-1}$ after 50 cycles, implying the importance of coating modification for natural graphite. When the addition of $\mathrm{AB}$ is $10 \%$, the first-cycle coulombic efficiency of $\mathrm{SG}+$ $10 \% \mathrm{AB}$ electrode is $74.4 \%$ and the reversible capacity attains 

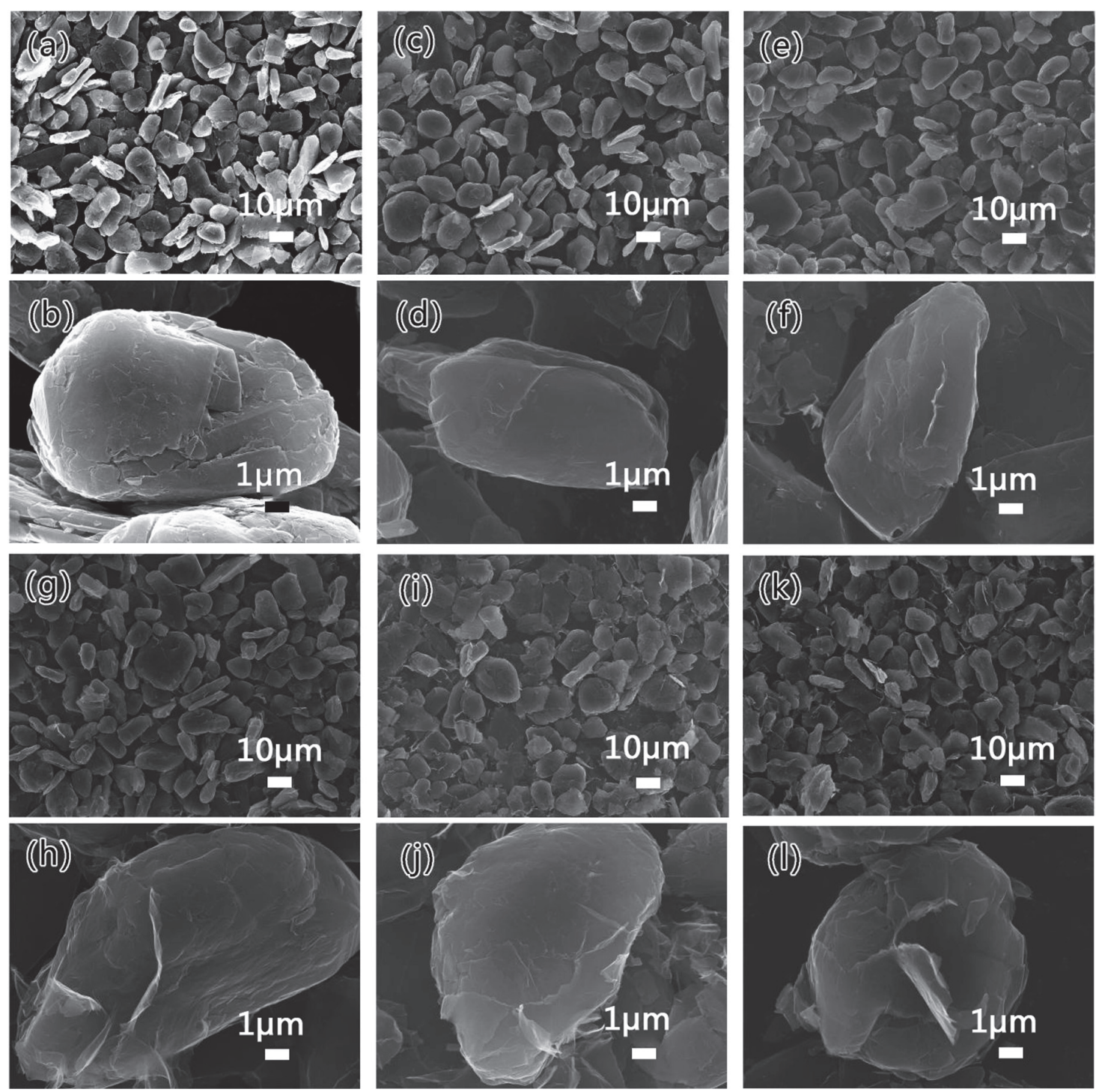

Fig. 2 SEM images of SG (a, b) and coated samples at different graphene contents: (c, d) $0.25 \%,(e, f) 0.5 \%,(g, h) 1 \%$, (i, j) $2.5 \%$ and $(k, l) 5 \%$ of graphene additive.
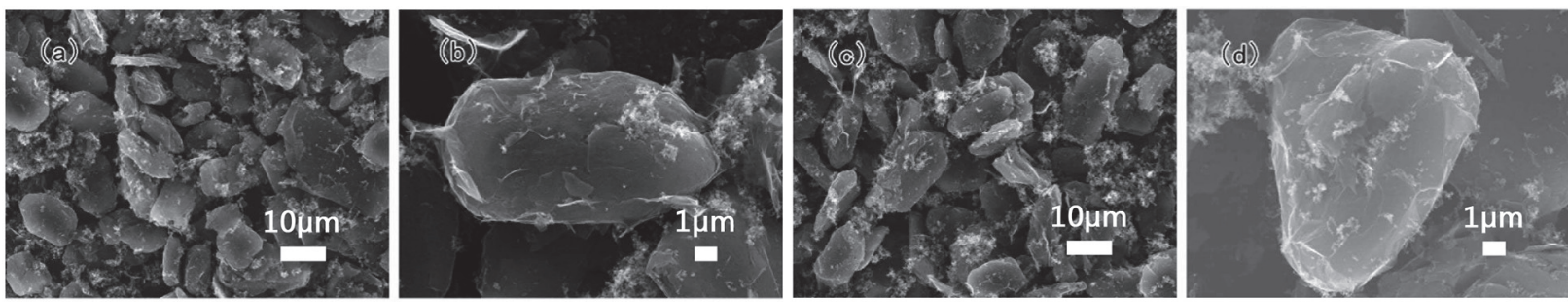

Fig. 3 SEM images of $(a, b)(2.5 \% \mathrm{G} / \mathrm{SG})+5 \% \mathrm{AB},(\mathrm{c}, \mathrm{d})(5 \% \mathrm{G} / \mathrm{SG})+5 \% \mathrm{AB}$.

$368.1 \mathrm{mAh} \cdot \mathrm{g}^{-1}$, but still exhibits poor cyclic stability. After 50 cycles, its reversible capacity declines to $343.9 \mathrm{mAh} \cdot \mathrm{g}^{-1}$. When the amount of graphene addition is $0.25 \%$, the G/SG electrode exhibits good cycling stability compared to the pure SG electrode. When graphene additives are $0.5 \%, 1 \%, 2.5 \%, 5 \%$, the reversible capacities of $\mathrm{G} / \mathrm{SG}$ electrodes after 50 cycles are $341.3,355,366,381.1 \mathrm{mAh} \cdot \mathrm{g}^{-1}$, respectively. And the reversible capacity retention after 50 cycles for G/SG electrodes are both more than $98 \%$. However, the capacity retentions of pure SG and SG $+10 \% \mathrm{AB}$ electrodes are only $92.9 \%$ and $93.4 \%$ after 50 cycles, respectively. When adding $1 \%$ graphene, the $1 \% \mathrm{G} / \mathrm{SG}$ electrode shows an equal reversible capacity in comparison with $\mathrm{SG}+10 \% \mathrm{AB}$ electrode, and even higher than $\mathrm{SG}+10 \% \mathrm{AB}$ electrode after 50 cycles. While when the amount of graphene additive is $2.5 \%$, the initial charge capacity and reversible capacity during 50 cycles are higher than that of $\mathrm{SG}+10 \% \mathrm{AB}$ electrode. The first-cycle coulombic efficiencies of $\mathrm{G} / \mathrm{SG}$ electrodes reach about $80 \%$, which is higher than those of SG (78.4\%) and $\mathrm{SG}+10 \% \mathrm{AB}(74.4 \%)$. The rate performance of $\mathrm{G} / \mathrm{SG}$, pure $\mathrm{SG}$ and $\mathrm{SG}+10 \% \mathrm{AB}$ electrodes at different current 
Table 1 Tap density and compaction density of SG, SG $+10 \%$ AB, G/SG and G/SG + 5\% AB at different graphene contents.

\begin{tabular}{ccc}
\hline Sample & Tap density $/\left(\mathrm{g} \cdot \mathrm{cm}^{-3}\right)$ & Compaction densit $/\left(\mathrm{g} \cdot \mathrm{cm}^{-3}\right)$ \\
\hline $\mathrm{SG}$ & 1.14 & 1.720 \\
$\mathrm{SG}+10 \% \mathrm{AB}$ & 1.08 & 1.690 \\
$0.25 \% \mathrm{G} / \mathrm{SG}$ & 1.10 & 1.717 \\
$0.5 \% \mathrm{G} / \mathrm{SG}$ & 1.05 & 1.704 \\
$1.0 \% \mathrm{G} / \mathrm{SG}$ & 0.99 & 1.699 \\
$2.5 \% \mathrm{G} / \mathrm{SG}$ & 0.94 & 1.670 \\
$5 \% \mathrm{G} / \mathrm{SG}$ & 0.91 & 1.665 \\
$(0.25 \% \mathrm{G} / \mathrm{SG})+5 \% \mathrm{AB}$ & 1.01 & 1.650 \\
$(0.5 \% \mathrm{G} / \mathrm{SG})+5 \% \mathrm{AB}$ & 0.95 & 1.648 \\
$(1.0 \% \mathrm{G} / \mathrm{SG})+5 \% \mathrm{AB}$ & 0.91 & 1.632 \\
$(2.5 \% \mathrm{G} / \mathrm{SG})+5 \% \mathrm{AB}$ & 0.86 & 1.614 \\
$(5 \% \mathrm{G} / \mathrm{SG})+5 \% \mathrm{AB}$ & 0.83 & 1.610 \\
\hline
\end{tabular}

densities is shown in Fig. 5c. All the G/SG electrodes illustrate a better rate performance than the pure SG electrode. When graphene additives are $1 \%, 2.5 \%$ and $5 \%$, the $\mathrm{G} / \mathrm{SG}$ electrodes exhibit better rate performance compared to the $\mathrm{SG}+10 \% \mathrm{AB}$ electrode. In particular, when graphene addition is $5 \%$, it depicts tenth-cycle discharge capacities of 364.9, 320.3, 195.2 and 82.5 $\mathrm{mAh} \cdot \mathrm{g}^{-1}$ at the current densities of $0.1,0.2,0.5$ and $1 \mathrm{~A} \cdot \mathrm{g}^{-1}$, respectively. When the current density returns to the initial current density of $50 \mathrm{~mA} \cdot \mathrm{g}^{-1}$, the capacity still maintains 381.3 $\mathrm{mAh} \cdot \mathrm{g}^{-1}$. While for $\mathrm{SG}+10 \% \mathrm{AB}$ electrode, the tenth-cycle discharge capacities are $283,180.5,67.5$ and $30.5 \mathrm{mAh} \cdot \mathrm{g}^{-1}$ at the current densities of $0.1,0.2,0.5$ and $1 \mathrm{~A} \cdot \mathrm{g}^{-1}$, respectively. And

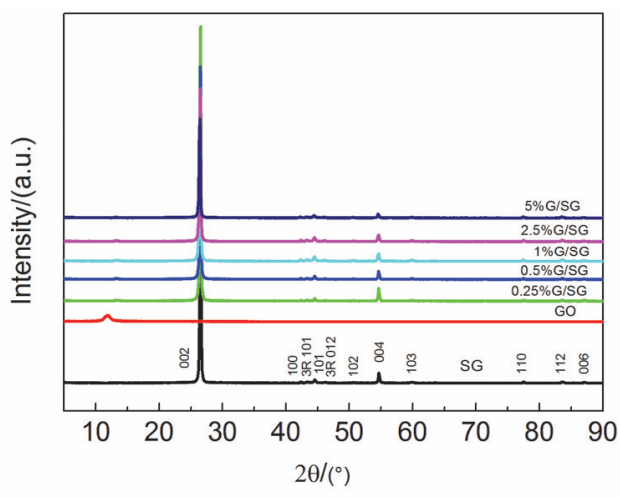

Fig. 4 XRD patterns of SG, GO and G/SG.

its capacity is only $344.8 \mathrm{mAh} \cdot \mathrm{g}^{-1}$ when the current density returns to $50 \mathrm{~mA} \cdot \mathrm{g}^{-1}$. Reversible capacity and capacity retentions of $\mathrm{G} / \mathrm{SG}$ and pure $\mathrm{SG}$ electrodes at a current density of $50 \mathrm{~mA} \cdot \mathrm{g}^{-1}$ for 50 cycles are shown in Fig. $5 \mathrm{~d}$. Compared with pure graphite, $\mathrm{G} / \mathrm{SG}$ electrodes show good electrochemical performance, particularly excellent rate performance.

When $5 \% \mathrm{AB}$ was added, the cycle performance and rate performance of $\mathrm{G} / \mathrm{SG}+5 \% \mathrm{AB}$ electrodes were further evaluated. As shown in Fig. 6a, the reversible capacities of $\mathrm{G} / \mathrm{SG}+5 \% \mathrm{AB}$ electrodes increase when $5 \% \mathrm{AB}$ is added. When graphene additives are $0.25 \%, 0.5 \%, 1 \%, 2.5 \%$ and $5 \%$, the reversible capacity after 50 cycles are $361.4,372.6,384.3,391.7$ and 404.5 $\mathrm{mAh} \cdot \mathrm{g}^{-1}$, respectively. And the electrodes also exhibit good cycle stability. The capacity retention of $\mathrm{G} / \mathrm{SG}+5 \% \mathrm{AB}$ electrodes are $99.4 \%, 98.1 \%, 99.1 \%, 98.9 \%$ and $98.3 \%$,

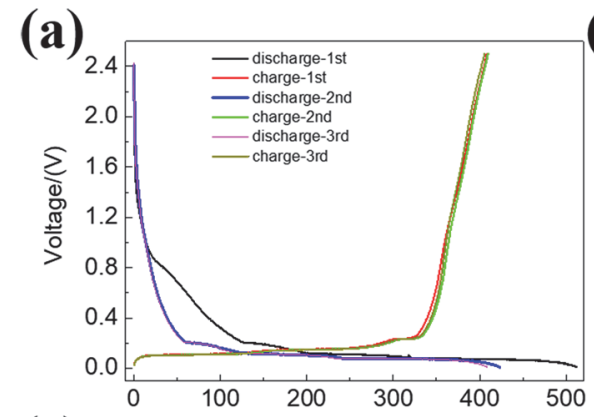

(c)

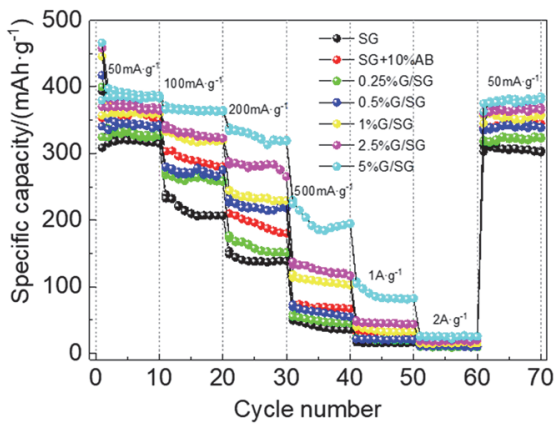

(b)

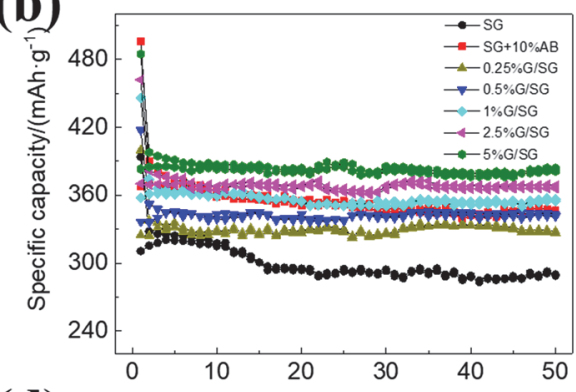

(d)

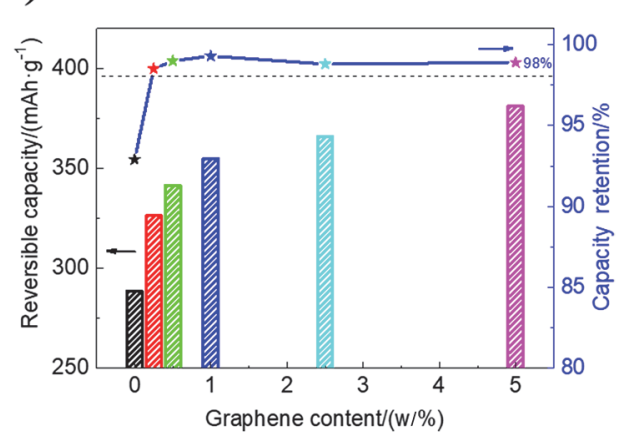

Fig. 5 (a) First three charge/discharge curves of 5\%G/SG at a current density of $50 \mathrm{~mA} \cdot \mathrm{g}^{-1}$. (b) Cycle performances of G/SG at different graphene contents, pure SG and SG $+10 \% \mathrm{AB}$ electrodes at a current density of $50 \mathrm{~mA} \cdot \mathrm{g}^{-1}$. (c) Rate performance of G/SG, pure SG and SG $+10 \%$ AB electrodes at different current densities. (d) Reversible capacity and capacity retentions of G/SG and pure SG electrodes after 50 cycles ( $w$, mass fraction). 

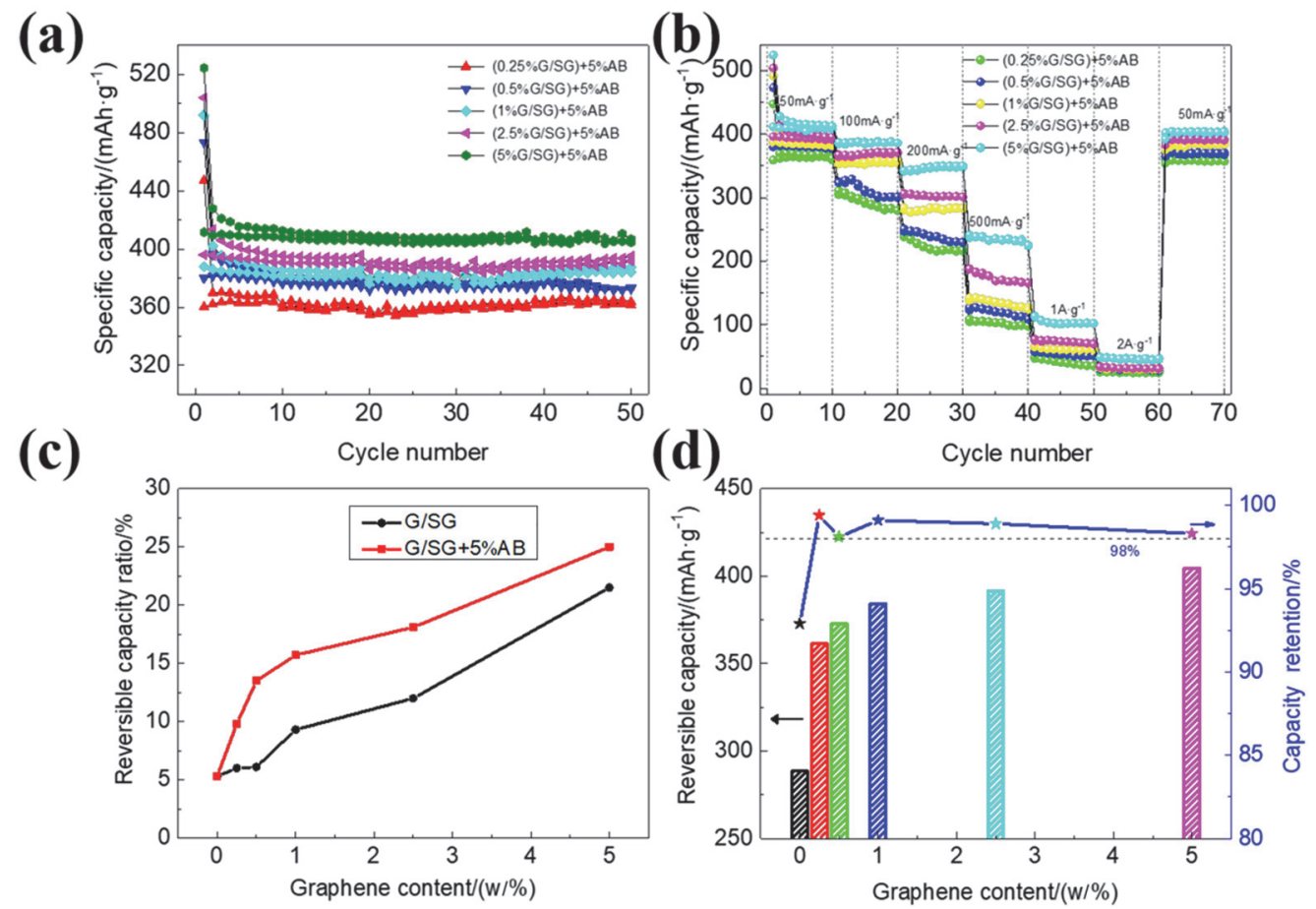

Fig. 6 (a) Cycle performance of $\mathrm{G} / \mathrm{SG}+5 \% \mathrm{AB}$ electrodes at a current density of $50 \mathrm{~mA} \cdot \mathrm{g}^{-1}$. (b) Rate performance of G/SG $+5 \% \mathrm{AB}$ electrodes at different current densities. (c) The ratios of reversible capacity at $1 \mathrm{~A} \cdot \mathrm{g}^{-1}$ to reversible capacity at $50 \mathrm{~mA} \cdot \mathrm{g}^{-1}$ ( $w$, mass fraction).

(d) Reversible capacity and capacity retentions of $\mathrm{G} / \mathrm{SG}+5 \% \mathrm{AB}$ and pure $\mathrm{SG}$ electrodes after 50 cycles ( $w$, mass fraction).

respectively. The $\mathrm{G} / \mathrm{SG}+5 \% \mathrm{AB}$ electrodes also exhibit a higher rate capacity, as plotted in Fig. 6 b. For $(5 \% \mathrm{G} / \mathrm{SG})+5 \% \mathrm{AB}$ electrode, the tenth-cycle discharge capacities are 407.8, 386, $347.8,224$ and $101.9 \mathrm{mAh} \cdot \mathrm{g}^{-1}$ at the current density of $0.05,0.1$, $0.2,0.5$ and $1 \mathrm{~A} \cdot \mathrm{g}^{-1}$, respectively. When the rate is reduced back to $50 \mathrm{~mA} \cdot \mathrm{g}^{-1}$, the capacity still maintains $402.2 \mathrm{mAh} \cdot \mathrm{g}^{-1}$. The ratios of reversible capacity at $1 \mathrm{~A} \cdot \mathrm{g}^{-1}$ to reversible capacity at $50 \mathrm{~mA} \cdot \mathrm{g}^{-1}$ are higher than those of $\mathrm{G} / \mathrm{SG}$ electrodes with corresponding graphene content are shown in Fig. 6c. Reversible capacity and capacity retentions of G/SG and pure SG electrodes after 50 cycles are shown in Fig. 6d. In short, G/SG $+5 \% \mathrm{AB}$ anode exhibits both higher reversible capacity and better rate performance compared with $\mathrm{G} / \mathrm{SG}$ electrode. It can be assigned to a better conductive network enhanced by graphene and $\mathrm{AB}$ synergistically. However, the first coulombic efficiency of G/SG + $5 \% \mathrm{AB}$ electrode is slightly lower than that with the same graphene content of G/SG electrode, as plotted in Table 2, which could be assigned to the increase of the surface area and the low first coulombic efficiency of AB. In comparison with adding graphene powder, the electrochemical results show that the G/SG electrodes deliver a high reversible capacity, high-rate performance and excellent cycling stability. Conducting agent of acetylene black plays significant roles in graphene-wrapped natural spherical graphite electrodes. Acetylene black particles connect to graphene-wrapped natural spherical graphite particles through the form of point contact, which is beneficial for the formation of a good conductive network. Therefore, the composites exhibit both higher reversible capacity and better rate performance compared with $\mathrm{G} / \mathrm{SG}$ electrode.
To investigate the kinetics of electrode process and further demonstrate the effect of $\mathrm{AB}$ addition on the electrode performance of graphene-wrapped natural spherical graphite, $\mathrm{AC}$ impedance measurements were carried out. The Nyquist impedance plots of $5 \% \mathrm{G} / \mathrm{SG}$ and $(5 \% \mathrm{G} / \mathrm{SG})+5 \% \mathrm{AB}$ electrodes after 10 cycles are presented in Fig. 7a. It is remarkable that all the Nyquist plots compose of two semicircles at a high and medium frequency regions and a slope line in the low frequency region. The high-frequency semicircle can be attributed to the formation of SEI films and contact resistance $\left(R_{\mathrm{f}}\right)$. The semicircle in the middle range is assigned to the charge-transfer resistance $\left(R_{\mathrm{ct}}\right)$ and the double layer capacitor. The slope line at

Table 2 The first-cycle coulombic efficiency data of SG, SG + 10\%AB, G/SG and G/SG $+5 \% \mathrm{AB}$ at different graphene contents electrodes.

\begin{tabular}{cc}
\hline Sample & The first-cycle coulombic efficiency $\%$ \\
\hline $\mathrm{SG}$ & 78.4 \\
$\mathrm{SG}+10 \% \mathrm{AB}$ & 74.4 \\
$0.25 \% \mathrm{G} / \mathrm{SG}$ & 81.2 \\
$0.5 \% \mathrm{G} / \mathrm{SG}$ & 80.6 \\
$1.0 \% \mathrm{G} / \mathrm{SG}$ & 80.2 \\
$2.5 \% \mathrm{G} / \mathrm{SG}$ & 80.0 \\
$5 \% \mathrm{G} / \mathrm{SG}$ & 78.9 \\
$(0.25 \% \mathrm{G} / \mathrm{SG})+5 \% \mathrm{AB}$ & 80.6 \\
$(0.5 \% \mathrm{G} / \mathrm{SG})+5 \% \mathrm{AB}$ & 80.3 \\
$(1.0 \% \mathrm{G} / \mathrm{SG})+5 \% \mathrm{AB}$ & 78.8 \\
$(2.5 \% \mathrm{G} / \mathrm{SG})+5 \% \mathrm{AB}$ & 78.6 \\
$(5 \% \mathrm{G} / \mathrm{SG})+5 \% \mathrm{AB}$ & 77.9 \\
\hline
\end{tabular}


(a)

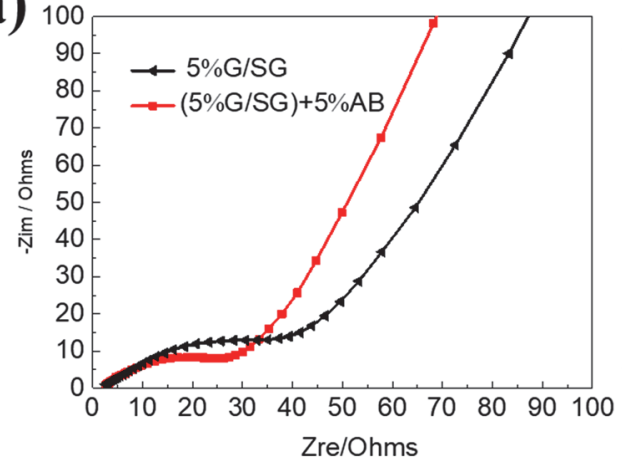

(b)

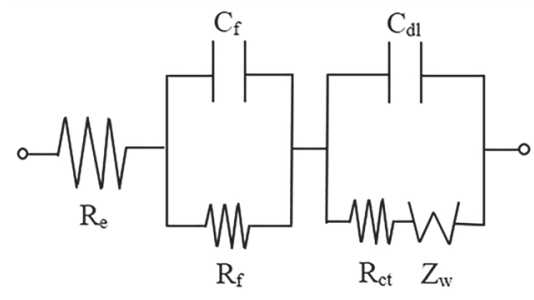

Fig. 7 (a) AC impedance spectra of 5\%G/SG and (5\%G/SG) + 5\%AB electrodes, (b) Randles equivalent circuit.

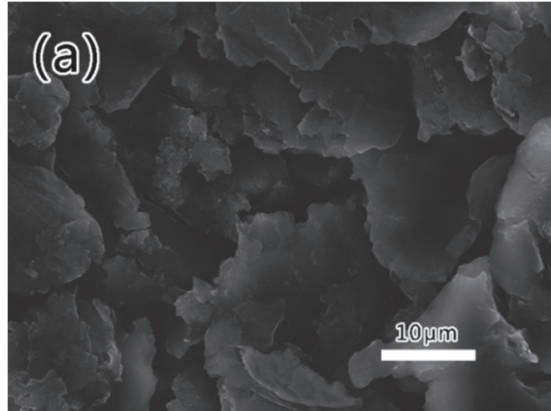

Fig. 8 SEM images of (a) SG $+10 \% \mathrm{AB}$ and (b) $5 \% \mathrm{G} / \mathrm{SG}$ electrodes after 50 discharge/charge cycles. low frequency range relates to the lithium-diffusion process. The EIS is modeled by an equivalent circuit ${ }^{27}$ shown in Fig. $7 \mathrm{~b}$, and the fitted impedance parameters are summarized in Table 3. $R_{\mathrm{e}}$ is the electrolyte resistance, and $C_{\mathrm{f}}$ and $R_{\mathrm{f}}$ are the capacitance and resistance of the surface film formed on the electrodes, respectively. $C_{\mathrm{dl}}$ and $R_{\mathrm{ct}}$ are the double-layer capacitance and charge-transfer resistance, respectively. $Z_{\mathrm{w}}$ is the Warburg impedance related to the diffusion of lithium ions into the bulk of graphite electrode. The $R_{\mathrm{f}}$ and $R_{\mathrm{ct}}$ values for the $(5 \% \mathrm{G} / \mathrm{SG})+$ $5 \% \mathrm{AB}$ electrode (3.08 and $11.24 \Omega$ ) are smaller than that of $5 \% \mathrm{G} / \mathrm{SG}(4.11$ and $14.81 \Omega$ ), indicating that the $\mathrm{AB}$ addition can enhance the electric conductivity of the G/SG electrode and thus enhance rapid electron transport during the lithium insert/extraction reaction, resulting in obvious improvement of the electrochemical performance.

The morphologies of $\mathrm{SG}+10 \% \mathrm{AB}$ and $5 \% \mathrm{G} / \mathrm{SG}$ electrodes after 50 discharge/charge cycles are exhibited in Fig. 8. As shown in Fig. 8a, a large gap appears between SG particles, indicating that the conductive network is interrupted. For the 5\%G/SG electrode shown in Fig. 8b, there are few gaps in the surface morphology, and the particles are more closely connected, indicating that the conductive network is better. The significant improvement of the electrochemical performance for

Table 3 Kinetic parameter of 5\%G/SG and $(5 \% \mathrm{G} / \mathrm{SG})+5 \% \mathrm{AB}$ electrodes.

\begin{tabular}{ccl}
\hline Sample & $R_{\mathrm{f}} / \Omega$ & $R_{\mathrm{ct}} / \Omega$ \\
\hline $5 \% \mathrm{G} / \mathrm{SG}$ & 4.11 & 14.81 \\
$(5 \% \mathrm{G} / \mathrm{SG})+5 \% \mathrm{AB}$ & 3.08 & 11.24 \\
\hline
\end{tabular}

graphene-wrapped SG could be probably attributed to the graphene wrapping. On one hand, the graphene shell enhances the structural integrity of the SG particles during the lithiation and delithiation processes, further improving the cycle stability of the materials. On the other hand, by bridging adjacent SG particles together, it provides a highly conductive network for electron transfer among the SG particles. The graphene in the composite materials could act not only as active material, but also as conductive agent to improve the electrochemical performance.

A model of conducting agent in the G/SG electrode is shown in Fig. 9. For G/SG material, we think that the main role of graphene shell is to enhance the structural integrity of the SG particles during the lithiation and delithiation process, and there still need $\mathrm{AB}$ particles to connect $\mathrm{G} / \mathrm{SG}$ particles through the form of point contact. $\mathrm{AB}$ particles fill into the gaps between G/SG particles, and a more effective conducting network is formed by graphene and $\mathrm{AB}$ synergistically. With the much

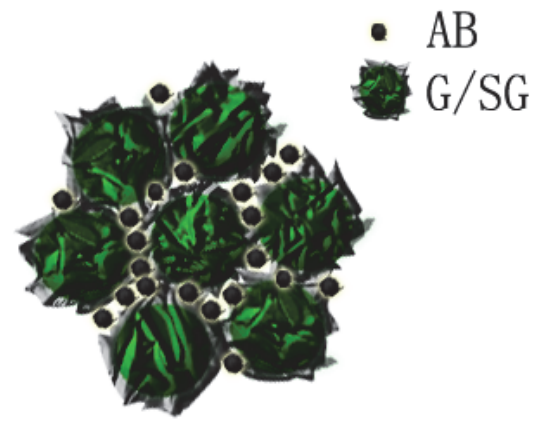

Fig. 9 The conducting model of the G/SG + 5\%AB electrode. 
faster charge-transfer process, the electrochemical performance of $\mathrm{G} / \mathrm{SG}$ was enhanced. Although graphene wrapping and $\mathrm{AB}$ addition exhibit positive effects on natural graphite electrode, such as increasing the electrical conductivity and enhancing the Li-storage performance including the reversible capacity, rate performance and cycle stability, the electrode density generally decreases with more graphene or $\mathrm{AB}$ addition, which should be considering the balance between gravimetric and volumetric capacities for graphite anode materials in practical applications.

\section{Conclusions}

Graphene-wrapped natural spherical graphite was successfully prepared using a simple two-step approach. The G/SG particles have a well spherical or ellipsoidal structure, and the SG particles were encapsulated by graphene sheets. Without the addition of acetylene black, the composites exhibit not only high specific capacities with higher first-cycle coulombic efficiencies, but also good cycle stability and rate performance. Furthermore, when 5\%AB was added, the composites exhibit both higher reversible capacity and better rate performance compared with $\mathrm{G} / \mathrm{SG}$ electrode. There still need $\mathrm{AB}$ particles to connect to $\mathrm{G} / \mathrm{SG}$ particles through the form of point contact. AB particles fill into the gaps between $\mathrm{G} / \mathrm{SG}$ particles, and a more effective conducting network is formed by graphene and $\mathrm{AB}$ synergistically. These results have great significance for further commercial application of natural graphite.

\section{References}

(1) Zaghib, K.; Song, X.; Guerfi, A.; Rioux, R.; Kinoshita, K. J. Power Sources 2003, 119, 8. doi: 10.1016/S0378-7753(03)00116-2

(2) Wang, G.; Zhang, B.; Yue, M.; Xu, X.; Qu, M.; Yu, Z. Solid State Ionics 2005, 176, 905. doi: 10.1016/j.ssi.2004.11.009

(3) Wu, Y. P.; Jiang, C.; Wan, C.; Holze, R. Solid State Ionics 2003, 156, 283. doi: 10.1016/S0167-2738(02)00680-X

(4) Park, C. M.; Jo, Y. N.; Park, J. W.; Yu, J. S.; Kim, J. S.; Choi, J.; Kim, Y. J. Bull. Korean Chem. Soc. 2014, 35, 2630. doi: 10.5012/bkcs.2014.35.9.2630

(5) Yeo, J. S.; Park, T. H.; Seo, M. H.; Miyawaki, J.; Mochida, I.; Yoon, S. H. Int. J. Electrochem. Sci. 2013, 8, 1308. doi: 10.1016/j.jelechem.2013.02.009

(6) Lee, J. H.; Kim, W. J.; Kim, J. Y.; Lim, S. H.; Lee, S. M. J. Power Sources 2008, 176, 353. doi: 10.1016/j.jpowsour.2007.09.119

(7) Choi, W. C.; Byun, D.; Lee, J. K.; Cho, B. W. Electrochim. Acta 2004, 50, 523. doi: 10.1016/j.electacta.2003.12.070

(8) Zhang, H.; Li, F.; Liu, C.; Cheng, H. J. Phys .Chem. C 2008, 112, 7767. doi: 10.1021/jp8003536

(9) Han, Y. J.; Kim, J.; Yeo, J. S.; An, J. C.; Hong, I. P.; Nakabayashi, K.; Miyawaki, J.; Jung, J. D.; Yoon, S. H. Carbon 2015, 94, 432. doi: 10.1016/j.carbon.2015.07.030
(10) Wan, C.; Li, H.; Wu, M.; Zhao, C. J. Appl. Electrochem. 2009, 39, 1081. doi: 10.1007/s10800-008-9761-6

(11) Lu, M.; Tian, Y.; Zheng, X.; Gao, J.; Huang, B. J. Power Sources 2012, 219, 188. doi: 10.1016/j.jpowsour.2012.07.044

(12) Novoselov, K. S.; Geim, A. K.; Morozov, S. V.; Jiang, D.; Zhang, Y.; Dubonos, S. V.; Grigorieva, I. V.; Firsov, A. A. Science 2004, 306, 666. doi: 10.1126/science. 1102896

(13) Geim, A. K.; Novoselov, K. S. Nat. Mater. 2007, 6, 183. doi: $10.1038 /$ nmat 1849

(14) Yoo, E. J.; Kim, J.; Hosono, E.; Zhou, H. S.; Kudo, T.; Honma, I. Nano Lett. 2008, 8, 2277. doi: 10.1021/n1800957b

(15) Su, F. Y.; You, C. H.; He, Y. B.; Lv, W.; Cui. W.; Jin, F.; Li, B.; Yang, Q. H.; Kang, F. J. Mater. Chem. 2010, 20, 9644. doi: 10.1039/C0JM01633K

(16) Su, F. Y.; He, Y. B.; Li, B.; Chen, X. C.; You, C. H.; Wei, W.; Lv, W.; Yang, Q. H.; Kang, F. Nano Energy 2012, 1, 429. doi: 10.1016/j.nanoen.2012.02.004

(17) Zhang, B.; Yu, Y.; Liu, Y.; Huang, Z. D.; He, Y. B.; Kim, J. K. Nanoscale 2013, 5, 2100. doi: 10.1039/c2nr33099g

(18) Guo, P.; Song, H.; Chen, X.; Ma, L.; Wang, G.; Wang, F. Anal. Chim. Acta 2011, 688, 146. doi: 10.1016/j.aca.2010.12.033

(19) Li, X. L.; Du, K.; Wang, H.; Song, H. F.; Liu, H. D.; Li, H. Y.; Zhang, Y. X.; Huang, J. M. Int. J. Electrochem. Sci. 2011, 6, 4411. doi: 10.1002/fuce. 201000173

(20) Li, X.; Song, H.; Du, K.; Zhang, Y.; Huang, J. Nanosci. Nanotechnol. Lett. 2012, 4, 191. doi: 10.1166/nnl.2012.1300

(21) Yin, L.H.; Wu, M. B.; Li, Y. P.; Wu, G. L.; Wang, Y. K.; Wang, Y. New Carbon Mater. 2017, 32, 311. doi: 10.1016/S1872-5805(17)60124-0

(22) An, H. F.; Jiang, L.; Li, F.; Wu, P.; Zhu, X. S.; Wei, S. H.; Zhou, Y. M. Acta Phys. -Chim. Sin. 2020, 36, 1905034. [安惠芳, 姜莉, 李峰, 吴平, 朱晓舒, 魏少华, 周益明. 物理化学学报, 2020, 36, 1905034.] doi: 10.3866/PKU.WHXB201905034

(23) Wu, D.; Niu, Y.; Wang, C.; Wu, H.; Li, Q.; Chen, Z.; Xu, B.; Li, H.; Zhang, L. J. Colloid Interface Sci. 2019, 552, 633. doi: 10.1016/j.jcis.2019.05.091

(24) Liu, X.; Liu, E.; Chao, D.; Chen, L.; Liu, S.; Wang, J.; Li, Y.; Zhao, J.; Kang, Y. M.; Shen, Z. RSC Adv. 2016, 6, 104010. doi: 10.1039/C6RA23228K

(25) Li, M.; Song, H.; Chen, X.; Zhou, J.; Ma, Z. Phys. Chem. Chem. Phys. 2015, 17, 3250. doi: 10.1039/c4cp04556d

(26) Bai, L.; Zhao, D.; Zhang, T.; Xie, W.; Zhang, J.; Shen, Z. Electrochim. Acta 2013, 107, 555. doi: 10.1016/j.electacta.2013.06.032

(27) Yang, S.; Song, H.; Chen, X. Electrochem. Commun. 2006, 8, 137. doi: 10.1016/j.elecom.2005.10.035 